\title{
Genetic analysis of the outer surface protein $C$ gene of Lyme disease spirochaetes (Borrelia burgdorferi sensu lato) isolated from rodents in Taiwan
}

\author{
CHIEN-MING SHIH and LI-LIAN CHAO \\ Department of Parasitology and Tropical Medicine, National Defense Medical Center, Taipei, Taiwan, Republic \\ of China
}

\begin{abstract}
The outer surface protein $\mathrm{C}$ gene (ospC) of Lyme disease spirochaetes (Borrelia burgdorferi sensu lato) was analysed for the first time in Taiwan. The genetic identities of these Taiwan isolates (TWKM1-7) were determined by restriction fragment length polymorphism (RFLP) analysis and sequence similarities of the PCR-amplified ospC gene amplicons. After cleavage by nuclease Dra I, differential fragment patterns of PCRamplified ospC DNA in relation to different genospecies of Lyme disease spirochaetes were observed and all of these Taiwan isolates were genetically affiliated to the genospecies of $\boldsymbol{B}$. burgdorferi sensu stricto. The phylogenetic analysis on the sequence similarity of these Taiwan isolates revealed a highly homogeneous genotype, ranging from $99.3 \%$ to $100 \%$, within the genospecies of $B$. burgdorferi sensu stricto and was distinguished from other genospecies of Borrelia isolates. The sequence similarity analysis also revealed the high sequence variability of the ospC gene among Borrelia strains that belong to the same genospecies but were isolated from different biological and geographical sources. Thus, these results provide the first investigation on the genetic identity of the ospC gene of these Taiwan isolates and show that these Taiwan isolates were closely related genetically to the genospecies of $B$. burgdorferi sensu stricto.
\end{abstract}

\section{Introduction}

Lyme disease is an emerging tick-borne spirochaetal infection [1] that can cause multisystem human illness with varying degrees of clinical symptoms among infected persons, ranging from a relatively benign skin lesion to severe arthritic, neurological and cardiac manifestations [2,3]. The aetiological agent of Lyme disease, Borrelia burgdorferi sensu lato, is transmitted mainly by ticks of the Ixodes ricinus complex in North America and Europe $[4,5]$ and by I. persulcatus and $I$. ovatus ticks in the countries of Far East Asia [6-8]. Although a human case of Lyme disease had been reported in Taiwan [9] and Borrelia spirochaetes were also isolated from rodents in the Taiwan area [10], the genetic diversity of spirochaetes as well as the tick vectors responsible for transmission in Taiwan need to be established.

Received 19 Oct. 2001; accepted 13 Nov. 2001

Corresponding author: Dr C.-M. Shih (e-mail: cmshih@ ndmctsgh.edu.tw).
The heterogeneity of molecular and immunological characteristics among isolates of $B$. burgdorferi sensu lato from different geographical and biological origins has been demonstrated previously [11-18]. On the basis of immunoreactivity with $B$. burgdorferi-specific monoclonal antibodies (MAbs), plasmid profiles and the clinical manifestations of the patient, the causative agents of Lyme disease can be classified into three major genospecies $-B$. burgdorferi sensu stricto, $B$. garinii and B. afzelii (group VS461) [19,20]. Furthermore, genomic analysis among Borrelia isolates by PCR-restriction fragment length polymorphism (RFLP) analysis and sequence similarity of a specific target gene has been shown to be useful for species identification and genomic typing of Borrelia isolates from various biological and geographical sources [2124].

The outer surface protein $\mathrm{C}$ gene $(\operatorname{osp} C)$ of $B$. burgdorferi sensu lato is located on a $27-\mathrm{kb}$ circular plasmid [25] and is highly heterogeneous with the nucleotide sequences differing among isolates of different species of Borrelia [26, 27]. Strain diversity 
as well as the genetic heterogeneity can be distinguished among different Borrelia isolates by their distinct RFLP types [28]. Thus, the objective of the present study was to characterise the genetic identity of Taiwan isolates by their differential restriction fragment patterns and sequence similarity of the PCR-amplified $o s p C$ gene amplicons.

\section{Materials and methods}

\section{Spirochaete strains and in-vitro cultivation}

Seventeen Borrelia isolates belonging to the three major genospecies of B. burgdorferi sensu lato were used for PCR, RFLP and phylogenetic analysis (Table 1). Spirochaetes were cultured at $34^{\circ} \mathrm{C}$ in a humidified incubator (Nuaire, Plymouth, MN, USA) with $\mathrm{CO}_{2} 5 \%$ in air and maintained in BSK-H medium (catalogue no. B3528; Sigma) supplemented with rabbit serum (catalogue no. R7136; Sigma) $6 \%$ as described previously [10]. All cultures were examined weekly for optimal growth of spirochaetes by dark-field microscopy (model BX-60, Olympus, Tokyo, Japan).

\section{Preparation of spirochaete DNA}

Total genomic DNA was extracted from all Borrelia isolates as described previously [29]. Briefly, (3-ml) samples of cultured spirochaetes grown to a density of c. $2 \times 10^{8}$ cells $/ \mathrm{ml}$ of medium were centrifuged for $10 \mathrm{~min}$ at $12000 \mathrm{~g}$ to pellet the spirochaetes. The pellets were washed twice with phosphate-buffered saline (PBS; pH 7.2) containing $5 \mathrm{mM} \mathrm{MgCl}_{2}$, resuspended in $150 \mu \mathrm{l}$ of distilled water and boiled for $10 \mathrm{~min}$. After centrifugation at $10000 \mathrm{~g}$ for $10 \mathrm{~s}$, the supernate was collected and the DNA concentration was determined spectrophotometrically with a DNA calculator (GeneQuant II; Pharmacia Biotech, Uppsala, Sweden).

Table 1. Strains of B. burgdorferi sensu lato analysed

\begin{tabular}{llll}
\hline & \multicolumn{2}{c}{ Origin } & \\
Genospecies & ospC gene \\
and strain no. & Biological & Geographical & accession no. \\
\cline { 2 - 3 } B. burgdorferi & sensu stricto & & \\
B31 & Tick & USA & AF411450 \\
JD 1 & Tick & USA & AF416424 \\
N40 & Tick & USA & AF416430 \\
CT27985 & Tick & USA & AF416428 \\
TB & Tick & USA & AF416431 \\
VS219 & Tick & Switzerland & AF416432 \\
CT20004 & Tick & France & AF416427 \\
ECM-NY86 & Human skin & USA & AF416429 \\
B. garinii & & & \\
K48 & Tick & Czechoslovakia & AF416425 \\
B. afzelii & & & \\
VS461 & Tick & Switzerland & AF416426 \\
Taiwan isolates & & & \\
TWKM1 & Mouse ear & Taiwan & AF411451 \\
TWKM2-7 & Mouse ear & Taiwan & AF416418-23 \\
\hline
\end{tabular}

\section{Genetic analysis by PCR and RFLP}

DNA samples extracted from the Taiwan isolates and other spirochaetes representative of the three major genospecies of $B$. burgdorferi sensu lato were used as template for PCR amplification of the $o s p C$ gene DNA. An ospC-specific primer set of CF1 (forward) 5'AAGTGCGATATTAATGAC-3' and CR2 (reverse) $5^{\prime}$ GATCTTTCTGCCACAACAG-3' were designed and synthesised by a custom oligonucleotide synthesis service (Gibco BRL, Taipei, Taiwan) as described previously [30]. All PCR reagents and TaqGold DNA polymerase were obtained from the GeneAmp kit and were used as recommended by the supplier (PerkinElmer Cetus, Taipei, Taiwan).

Briefly, a total of 20-pmol of the appropriate primer set and various amounts of template DNA were used in each $50-\mu 1$ reaction mixture. PCR amplification was performed with a Perkin-Elmer Cetus thermocycler (GeneAmp system 9700) and with amplification for 30 cycles of denaturation at $92^{\circ} \mathrm{C}$ for $30 \mathrm{~s}$, annealing at $41^{\circ} \mathrm{C}$ for $30 \mathrm{~s}$, and extension at $72^{\circ} \mathrm{C}$ for $90 \mathrm{~s}$. PCRamplified DNA products were electrophoresed on agarose $2 \%$ gels in TBE buffer and were visualised under UV light after staining with ethidium bromide. The 1-kb plus DNA ladder (catalogue no. 10787-018, Gibco BRL, Taipei, Taiwan) was used as the standard marker for comparison. After purification with a QIAquick PCR purification kit (catalogue no. 28104, Qiagen, Taipei, Taiwan), the purified PCR products were digested with restriction endonuclease Dra I (New England Biolabs, Taipei, Taiwan) according to the manufacturer's instructions. The digested DNA fragments were separated by electrophoresis in agarose $3.5 \%$ gels (Agarose-1000, Gibco BRL) and visualised under UV light with ethidium bromide staining. DNA ladders of 1-kb plus and $50 \mathrm{bp}$ (10416-014, Gibco $\mathrm{BRL})$ fragments were used as the standard markers for comparison.

\section{Sequence alignments and phylogenetic analysis}

The nucleotide sequences of the $o s p C$ gene amplicon of the Borrelia isolates used in this study were sequenced by a dye-deoxy terminator reaction method with the bigdye terminator-Taq cycle sequencing kit and an ABI Prism 377-96 DNA sequencer (Applied Biosystems, Foster City, CA, USA). The determined sequences were aligned and a similarity matrix and neighbour-joining phylogenetic tree were constructed with the DNASTAR program and the CLUSTAL V software package [31,32].

\section{Nucleotide sequence accession numbers}

The nucleotide sequences of PCR-amplified ospC gene amplicons determined in this study have been registered and assigned the following GenBank accession numbers: strains B31 (AF411450), TWKM1 (AF411 
451), TWKM2 (AF416418), TWKM3 (AF416419), TWKM4 (AF416420), TWKM5 (AF416421), TWK M6 (AF416422), TWKM7 (AF416423), JD1 (AF41 6424), K48 (AF416425), VS461 (AF416426), CT 20004 (AF416427), CT27985 (AF416428), ECMNY86 (AF416429), N40 (AF416430), TB (AF416431) and VS219 (AF416432).

\section{Results}

The $o s p C$ gene was amplified by PCR to generate the ospC DNA of all the Taiwan isolates and another 10 isolates belonging to three major genospecies of Lyme disease spirochaetes. A DNA fragment of $c$. $630 \mathrm{bp}$ was generated and observed in an agarose $2 \%$ gel (Fig. 1). These results demonstrate that the $\operatorname{ssp} C$ genes were highly conserved in all the Borrelia isolates regardless of their origin and the genospecies of the Lyme disease spirochaetes.

To clarify the genomic identity of these Taiwan isolates, PCR-RFLP analysis of the ospC gene amplicon was also performed for further characterisation of Borrelia isolates belonging to the three major genospecies of Lyme disease spirochaetes. After cleavage by $\mathrm{Dra}$, the restriction site polymorphism of the $\operatorname{spC}$ gene amplicons from the 17 Borrelia isolates was investigated by comparing their restriction patterns of digested DNA fragments. All 17 isolates could be classified into four different RFLP patterns (Fig. 2) in relation to three different genospecies of $B$. burgdorferi sensu lato. The restriction fragment pattern of DraI-digested ospC gene amplicon of the genospecies B. garinii (strain K48) demonstrated a specific pattern (type B) with DNA fragments of c. 260, 220
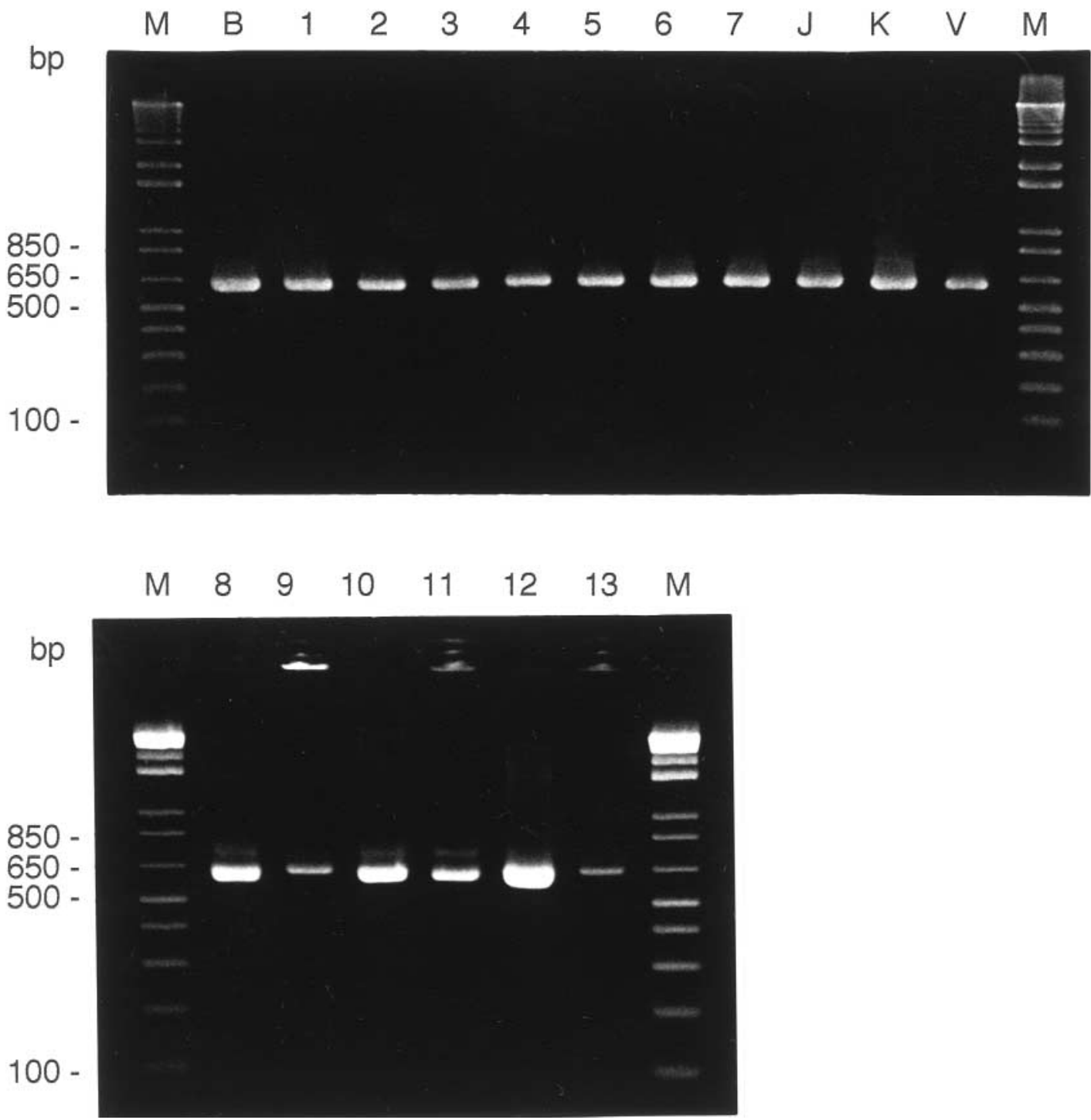

Fig. 1. PCR analysis with a primer set specific for the ospC genes of B. burgdorferi sensu lato. Lane B, isolate B31; lanes 1-7 represent the Taiwan isolates of TWKM1-7, respectively; lane $\mathbf{J}$, isolate JD 1 of B. burgdorferi sensu stricto; lane $\mathbf{K}$, isolate K48 of B. garinii; lane V, isolate VS461 of B. afzelii; lanes 8-13 represent the B. burgdorferi sensu stricto strains CT20004, CT27985, ECM-NY86, N40, TB and VS219, respectively; lane M, 1-kb plus DNA ladder (Gibco BRL). The amplification products were electrophoresed on agarose 2\% gels (Agarose-LE, USB, Cleveland, OH, USA) and DNA fragments of $c$. 630 bp were visualised under UV light with ethidium bromide staining. 

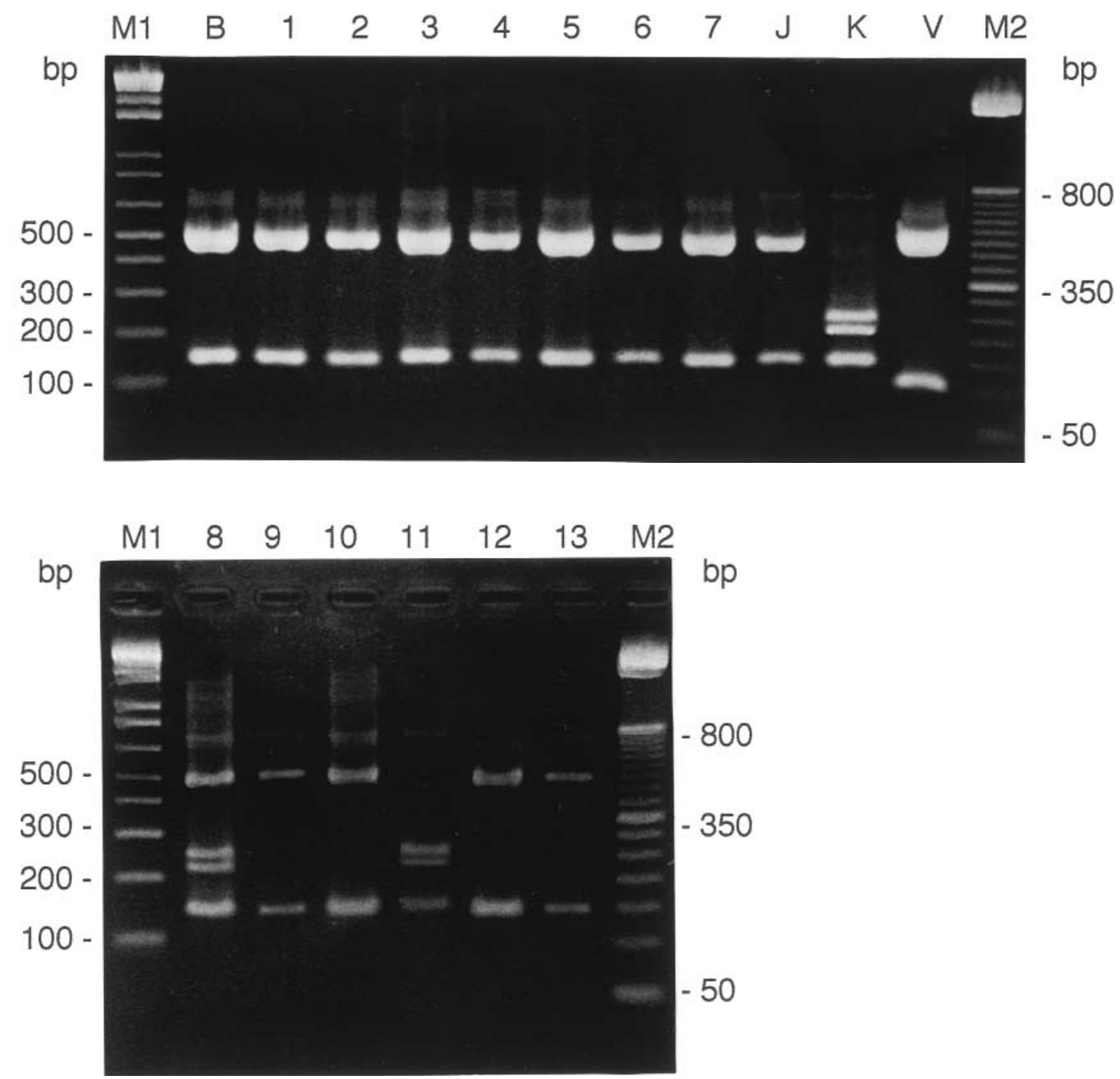

Fig. 2. PCR-RFLP analysis of the restriction patterns of $\operatorname{sp} P$ genes from Taiwan isolates and isolates of other genospecies of $B$. burgdorferi. The amplification products were further purified by a QIAquick PCR purification kit (Qiagen) and were digested with restriction endonuclease DraI. The digested DNA fragments were electrophoresed on an agarose 3.5\% gel (Agarose-1000, Gibco $\mathrm{BRL}$ ), stained with ethidium bromide and visualised by UV transillumination. Lane B, isolate B31; lanes 1-7 represent the Taiwan isolates TWKM1-7, respectively; lane $\mathbf{J}$, isolate JD 1 of $B$. burgdorferi sensu stricto; lane $\mathbf{K}$, isolate K48 of B. garinii; lane $\mathbf{V}$, isolate VS461 of B. afzelii; lanes 8-13 represent the B. burgdorferi sensu stricto strains CT20004, CT27985, ECM-NY86, N40, TB and VS219, respectively; lanes M1 and M2 represent the 1-kb plus and 50-bp DNA ladders (Gibco BRL), respectively.

and $150 \mathrm{bp}$, and a specific pattern (type C) with DNA fragments of $c .510$ and $120 \mathrm{bp}$ was also observed with the ospC gene amplicon of $B$. afzelii (strain VS461). All seven Taiwan isolates exhibited the same pattern (type AI) as the other six strains of B. burgdorferi sensu stricto with DNA fragments of $c .480$ and $150 \mathrm{bp}$ (Table 2). However, a different restriction fragment pattern (type AII) was observed in the DraI-digested ospC amplicons of strains N40 and CT20004 with DNA fragments of $c .270,230$ and $150 \mathrm{bp}$. These results revealed the genetic diversity of $\operatorname{ospC}$ genes among Borrelia isolates from different origins or of different genospecies of B. burgdorferi sensu lato. All of these Taiwan isolates were genetically related to the genospecies B. burgdorferi sensu stricto.

The sequence similarity of the $o s p C$ gene was analysed to identify the homogeneity of the Taiwan isolates in relation to the genospecies of $B$. burgdorferi sensu lato. As shown in Table 3, the nucleotide sequences of $o s p C$ gene amplicons were highly homogeneous and ranged from 99.3 to $100 \%$ among Taiwan isolates and the other four Borrelia isolates (strains B31, JD1, CT27985 and TB) within the genospecies B. burgdorferi sensu stricto. However, the homogeneity of ospC nucleotide sequences among the strains N40, ECMNY86, VS219 and CT20004 ranged from 71.4 to $80.0 \%$ in comparison to the genospecies B. burgdorferi sensu stricto (Table 3). Furthermore, the ospC sequence of strains K48 (B. garinii) and VS461 (B. afzelii) showed a homogeneity of only $65.4-74.6 \%$ and $65.6-77.9 \%$, respectively.

The phylogenetic relationships based on the sequence alignment of $o s p C$ gene were also analysed to demonstrate the divergence among Borrelia isolates investigated in this study. As compared with the aligned sequence of isolate B31, highly variable nucleotide 
Table 2. RFLP analysis of restriction patterns of the $o s p C$ gene from Taiwan isolates and other genospecies of B. burgdorferi sensu lato

\begin{tabular}{lclc}
\hline $\begin{array}{l}\text { Genospecies } \\
\text { and strain no. }\end{array}$ & $\begin{array}{c}\text { Estimated PCR } \\
\text { product (bp) }\end{array}$ & $\begin{array}{l}\text { Dra I restriction } \\
\text { fragment sizes (bp) }\end{array}$ & $\begin{array}{c}\text { RFLP } \\
\text { type }\end{array}$ \\
\hline B. burgdorferi sensu & stricto & & \\
B31 & 630 & 150,480 & AI \\
JD1 & 630 & 150,480 & AI \\
N40 & 630 & $150,230,270$ & AII \\
CT27985 & 630 & 150,480 & AI \\
TB & 630 & 150,480 & AI \\
VS219 & 630 & 150,480 & AI \\
CT20004 & 630 & $150,230,270,500^{*}$ & AII \\
ECM-NY86 & 630 & 150,480 & AI \\
Taiwan isolates & & & \\
TWKM1-7 & 630 & 150,480 & AI \\
B. garinii & & & \\
K48 & 630 & $150,220,260$ & $\mathrm{~B}$ \\
B. afzelii & & & $\mathrm{C}$ \\
VS461 & 630 & 120,510 & \\
*Incomplety digested &
\end{tabular}

*Incompletely digested DNA fragment.

sequences were observed in strains CT20004, VS219, ECM-NY86 and N40, with a sequence divergence of $15-21 \%$ within the genospecies B. burgdorferi sensu stricto (Fig. 3). However, these sequences can be distinguished from those of strains K48 (B. garinii) and VS461 (B. afzelii). Furthermore, all the Taiwan isolates were very similar to strains B31, JD1, TB and CT27985 with a sequence divergence $<0.5 \%$. These results reveal the heterogeneity of the $\operatorname{ospC}$ gene among Borrelia isolates within the same genospecies as well as between the genospecies of $B$. burgdorferi sensu lato and all of these Taiwan isolates could be verified as belonging to the genospecies $B$. burgdorferi sensu stricto.

\section{Discussion}

This report describes the first genomic characterisation and classification of the ospC gene among Lyme disease spirochaetes (B. burgdorferi sensu lato) isolated in Taiwan. In previous investigations, the protein profiles of these Taiwan isolates were consistent with the major protein bands of other documented strains of Lyme disease spirochaetes and their antigenicity was also verified by their reactivities with MAbs specific for B. burgdorferi sensu lato [29]. Although the heterogeneity among major protein bands and the immunoreactivity with $B$. burgdorferi-specific MAbs had been used for the typing or species identification of Lyme disease isolates, the validity of these methods for genospecies identification was not fully satisfied $[14,33]$. Thus, genomic analysis based on the ospC genes may provide a reliable and useful method for species identification of Borrelia spirochaetes that exist in various animal reservoirs and vector ticks of Taiwan.

Although genetic analysis based on the genospeciesspecific PCR primers had been recognised as a rapid and definitive assay for species identification of Borrelia spirochaetes from various biological and geographical origins [14,21-24,33], it was difficult to clarify the genetic diversity among Borrelia isolates at the intraspecies level [34]. Moreover, genetic heterogeneity can be determined among Borrelia isolates that were previously identified as the same genospecies or atypical strains of spirochaetes $[28,35,36]$. In a previous study, the genetic relationship of these Taiwan isolates was determined to be the same genospecies by their differential reactivities with genospecies-specific PCR primers based on the ospA gene of B. burgdorferi sensu lato [29]. Results from the present study further clarify the genetic identity of these Taiwan isolates by analysing the $\operatorname{spC} C$ gene amplicons and all these Taiwan isolates were genetically classified into one subtype (AI) within the genospecies B. burgdorferi sensu stricto.

The genetic heterogeneity of Borrelia isolates can be classified according to their differential restriction fragment patterns by RFLP analysis of specific target genes [21,37-39]. Previous reports concluded that RFLP analysis of the $\operatorname{ssp} C$ genes seemed useful for detection of mixed spirochaetal infections and classification of the genospecies of Borrelia isolates detected in various biological specimens [25-28, 38]. Results of the present study also demonstrate that the genospecies could be determined among different Borrelia isolates by their restriction fragment patterns of the $\operatorname{osp} C$ gene and reveal two subgroups within the genospecies $B$. burgdorferi sensu stricto (Fig. 2 and Table 2). All the Taiwan isolates were genetically linked to one major subgroup (AI) according to the homogeneity of RFLP pattern within the same genospecies of Borrelia. These observations suggest that the genomic identity of Borrelia isolates can be determined either interspecies or intraspecies in B. burgdorferi sensu lato by analysing the restriction polymorphisms of DraIdigested $\operatorname{spC} C$ gene amplicons.

The phylogenetic relationships among Borrelia isolates can be determined by analysing the sequence similarity of a specific target gene. Sequence analysis of the ospC gene among Borrelia isolates had been shown to be useful for evaluating the taxonomic relatedness of $B$. burgdorferi sensu lato isolates derived from various geographical and biological sources [25-28]. The phylogenetic analysis of the $\operatorname{ssp} C$ gene sequence of isolates previously identified as the same or atypical strains of Borrelia also differentiated new ribotype groups within the same genospecies of Lyme disease spirochaetes [26]. Moreover, nucleotide sequence variation of a target gene may actually represent genetic divergence within the genospecies of Borrelia isolates and genetic exchange by lateral transfer of the ospC sequence is proposed to be the mechanism responsible for the relatively high levels of $\operatorname{ss} C$ gene diversity [27,28]. In this study, the phylogenetic analysis of the $\operatorname{spC}$ gene among 17 Borrelia isolates 
Table 3. Sequence similarity between $\operatorname{ospC}$ gene sequences from Taiwan isolates and isolates of other genospecies of Borrelia*

\begin{tabular}{|c|c|c|c|c|c|c|c|c|c|c|c|c|c|c|c|c|c|}
\hline \multirow[b]{2}{*}{ Strain no. } & \multicolumn{17}{|c|}{ Sequence similarity (\%) to strain no. } \\
\hline & B31 & Twkm1 & Twkm2 & Twkm3 & Twkm4 & Twkm5 & Twkm6 & Twkm7 & JD-1 & K48 & VS461 & CT20004 & CT27985 & $\begin{array}{l}\text { ECM- } \\
\text { NY86 }\end{array}$ & $\mathrm{N} 40$ & TB & VS219 \\
\hline B31 & 100.0 & 99.6 & 99.8 & 99.8 & 100.0 & 99.6 & 99.5 & 99.3 & 99.3 & 74.5 & 77.9 & 80.0 & 99.7 & 76.8 & 79.3 & 100.0 & 71.6 \\
\hline Twkm-1 & & 100.0 & 99.8 & 99.3 & 99.6 & 99.1 & 99.6 & 99.6 & 99.6 & 74.1 & 77.5 & 79.8 & 99.6 & 77.3 & 79.1 & 99.5 & 72.1 \\
\hline Twkm-2 & & & 100.0 & 99.6 & 99.8 & 99.1 & 99.8 & 99.8 & 99.8 & 74.5 & 77.7 & 79.8 & 99.8 & 77.4 & 79.3 & 99.6 & 71.9 \\
\hline Twkm-3 & & & & 100.0 & 99.8 & 98.9 & 99.8 & 99.8 & 99.8 & 74.1 & 77.6 & 79.7 & 99.8 & 77.1 & 79.0 & 99.1 & 71.4 \\
\hline Twkm-4 & & & & & 100.0 & 99.6 & 99.5 & 99.3 & 99.3 & 74.5 & 77.9 & 80.0 & 99.7 & 76.8 & 79.3 & 100.0 & 71.6 \\
\hline Twkm-5 & & & & & & 100.0 & 99.1 & 99.3 & 99.3 & 74.3 & 77.5 & 79.8 & 99.6 & 77.2 & 79.3 & 99.8 & 71.8 \\
\hline Twkm-6 & & & & & & & 100.0 & 99.8 & 99.8 & 74.6 & 77.4 & 79.4 & 99.1 & 76.7 & 78.7 & 99.3 & 71.1 \\
\hline Twkm-7 & & & & & & & & 100.0 & 100.0 & 74.6 & 77.4 & 79.4 & 99.3 & 76.7 & 78.9 & 99.3 & 71.4 \\
\hline $\mathrm{JD}-1$ & & & & & & & & & 100.0 & 74.6 & 77.4 & 79.4 & 99.3 & 76.7 & 78.9 & 99.3 & 71.4 \\
\hline K48 & & & & & & & & & & 100.0 & 77.3 & 71.1 & 74.5 & 70.2 & 77.0 & 74.5 & 65.4 \\
\hline VS461 & & & & & & & & & & & 100.0 & 73.7 & 77.7 & 70.6 & 76.2 & 77.8 & 65.6 \\
\hline СТ20004 & & & & & & & & & & & & 100.0 & 79.8 & 75.8 & 75.0 & 79.9 & 70.1 \\
\hline СТ27985 & & & & & & & & & & & & & 100.0 & 76.0 & 79.3 & 99.8 & 72.1 \\
\hline ECM-NY86 & & & & & & & & & & & & & & 100.0 & 69.0 & 77.6 & 89.4 \\
\hline $\mathrm{N} 40$ & & & & & & & & & & & & & & & 100.0 & 79.4 & 65.6 \\
\hline TB & & & & & & & & & & & & & & & & 100.0 & 72.0 \\
\hline VS219 & & & & & & & & & & & & & & & & & 100.0 \\
\hline
\end{tabular}

*Strains B31, JD1, CT20004, CT27985, ECM-NY86, N40, TB and VS219, B burgdorferi sensu stricto; K48, B garinii; VS461, B. afzelii. 


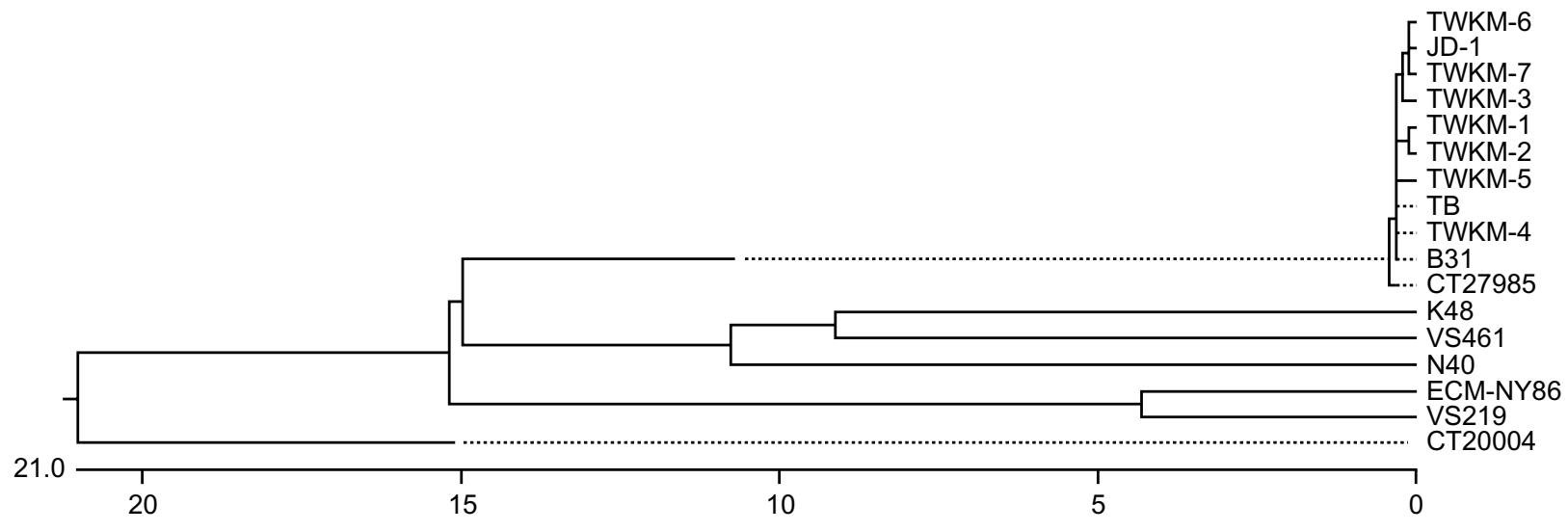

Fig. 3. Phylogenetic tree based on a comparison of the $\operatorname{sp} C$ gene sequences from 7 Taiwan isolates and 10 strains of $B$. burgdorferi sensu lato. The bar represents the divergence beween sequences of these Borrelia isolates.

demonstrated a high sequence heterogeneity between different genospecies and within the same genospecies of B. burgdorferi sensu stricto (Fig. 3). Further investigation on the sequence analysis of ospC genes of Borrelia strains isolated from various reservoir hosts, vector ticks and patients would help to clarify the genetic divergence of Borrelia isolates in Taiwan.

In conclusion, this report describes the first identification and characterisation of the $\operatorname{sspC}$ gene of Borrelia spirochaetes isolated in Taiwan. On the basis of their differential RFLP patterns and sequence similarity of their ospC genes, all these Taiwan isolates were genetically related to the genospecies of $B$. burgdorferi sensu stricto. Further application of this molecular tool to identify the genetic variability of the $\operatorname{ospC}$ genes from Borrelia isolates from patients, reservoir animals and vector ticks may help to illustrate the significance of the diversity of Borrelia spirochaetes in relation to the epidemiological features of human Lyme borreliosis in Taiwan.

\section{References}

1. Burgdorfer W, Barbour AG, Hayes SF, Benach JL, Grunwaldt E, Davis JP. Lyme disease - a tick-borne spirochetosis? Science 1982; 216: 1317-1319.

2. Steere AC. Lyme disease. N Engl J Med 1989; 321: 586-596.

3. Steere AC, Bartenhagen NH, Craft JE et al. The early clinical manifestations of Lyme disease. Ann Intern Med 1983; 99: $76-82$.

4. Matuschka F-R, Lange R, Spielman A, Richter D, Fischer P. Subadult Ixodes ricinus (Acari: Ixodidae) on rodents in Berlin, West Germany. J Med Entomol 1990; 27: 385-390.

5. Spielman A, Wilson ML, Levine JF, Piesman J. Ecology of Ixodes dammini-borne human babesiosis and Lyme disease. Annu Rev Entomol 1985; 30: 439-460.

6. Ai CX, Wen YX, Zhang YG et al. Clinical manifestations and epidemiological characteristics of Lyme disease in Hailin County, Heilongjiang Province, China. Ann NY Acad Sci 1988; 539: 302-313.

7. Kawabata M, Baba S, Iguchi K, Yamaguti N, Russell H. Lyme disease in Japan and its possible incriminated tick vector, Ixodes persulcatus. J Infect Dis 1987; 156: 854.

8. Nakao M, Miyamoto K, Uchikawa K, Fujita H. Characterization of Borrelia burgdorferi isolated from Ixodes persulcatus and Ixodes ovatus ticks in Japan. Am J Trop Med Hyg 1992; 47: $505-511$.
9. Shih C-M, Wang J-C, Chao L-L, Wu T-N. Lyme disease in Taiwan: first human patient with characteristic erythema chronicum migrans skin lesion. J Clin Microbiol 1998; 36: 807-808

10. Shih C-M, Chao L-L. Lyme disease in Taiwan: primary isolation of Borrelia burgdorferi-like spirochetes from rodents in the Taiwan area. Am J Trop Med Hyg 1998; 59: 687-692.

11. Adam T, Gassmann GS, Rasiah C, Göbel UB. Phenotypic and genotypic analysis of Borrelia burgdorferi isolated from various sources. Infect Immun 1991; 59: 2579-2585.

12. Barbour AG, Heiland RA, Howe TR. Heterogeneity of major proteins in Lyme disease borreliae: a molecular analysis of North American and European isolates. J Infect Dis 1985; 152: 478-484.

13. Bergstrom S, Bundoc VG, Barbour AG. Molecular analysis of linear plasmid-encoded major surface proteins, OspA and OspB, of the Lyme disease spirochete Borrelia burgdorferi. Mol Microbiol 1989; 3: 479-486.

14. Jonsson M, Noppa L, Barbour AG, Bergström S. Heterogeneity of outer surface proteins in Borrelia burgdorferi: comparison of osp operons of three isolates of different geographic origins. Infect Immun 1992; 60: 1845-1853.

15. Lane RS, Pascocello JA. Antigenic characteristics of Borrelia burgdorferi isolated from Ixodid ticks in California. J Clin Microbiol 1989; 27: 2344-2349.

16. Lefebvre RB, Lane RS, Perng G-C, Brown JA, Johnson RC. DNA and protein analyses of tick-derived isolates of Borrelia burgdorferi from California. J Clin Microbiol 1990; 28: $700-707$.

17. Masuzawa T, Okada Y, Yanagihara Y, Sato N. Antigenic properties of Borrelia burgdorferi isolated from Ixodes ovatus and Ixodes persulcatus in Hokkaido, Japan. J Clin Microbiol 1991; 29: 1568-1573.

18. Wilske B, Preac-Mursic V, Schierz G, Kühbeck R, Barbour AG, Kramer M. Antigenic variability of Borrelia burgdorferi. Ann NY Acad Sci 1988; 539: 126-143.

19. Baranton G, Postic D, Saint Girons I et al. Delineation of Borrelia burgdorferi sensu stricto, Borrelia garinii sp. nov., and group VS461 associated with Lyme borreliosis. Int $J$ Syst Bacteriol 1992; 42: 378-383.

20. Johnson RC, Schmid GP, Hyde FW, Steigerwalt AG, Brenner DJ. Borrelia burgdorferi sp. nov.: etiologic agent of Lyme disease. Int J Syst Bacteriol 1984; 34: 496-497.

21. Demaerschalck I, Messaoud AB, De Kesel M. Simutaneous presence of different Borrelia burgdorferi genospecies in biological fluids of Lyme disease patients. J Clin Microbiol 1995; 33: 602-608.

22. Marconi RT, Garon CF. Development of polymerase chain reaction primer sets for diagnosis of Lyme disease and for species-specific identification of Lyme disease isolates by $16 \mathrm{~S}$ rRNA signature nucleotide analysis. J Clin Microbiol 1992; 30: $2830-2834$.

23. Marconi RT, Lubke L, Hauglum W, Garon CF. Species-specific identification of and distinction between Borrelia burgdorferi genomic groups by using 16S rRNA-directed oligonucleotide probes. J Clin Microbiol 1992; 30: 628-632.

24. Rosa PA, Hogan D, Schwan TG. Polymerase chain reaction 
analyses identify two distinct classes of Borrelia burgdorferi. J Clin Microbiol 1991; 29: 524-532.

25. Marconi RT, Samuels DS, Garon CF. Transcriptional analyses and mapping of the OspC gene in Lyme disease spirochetes. $J$ Bacteriol 1993; 175: 926-932.

26. Fukunaga $M$, Hamase A. Outer surface protein $C$ gene sequence analysis of Borrelia burgdorferi sensu lato isolates from Japan. $J$ Clin Microbiol 1995; 33: 2415-2420.

27. Jauris-Heipke S, Liegl G, Preac-Mursic V et al. Molecular analysis of the gene encoding the outer surface protein $\mathrm{C}$ (OspC) of Borrelia burgdorferi sensu lato: relationship to ospA genotype and evidence of lateral gene exchange of ospC. J Clin Microbiol 1995; 33: 1860-1866.

28. Livey I, Gibbs CP, Schuster R, Dorner F. Evidence for lateral transfer and recombination in OspC variation in Lyme disease Borrelia. Mol Microbiol 1995; 18: 257-269.

29. Shih C-M, Chang H-M, Chen S-L, Chao L-L. Genospecies identification and characterization of Lyme disease spirochetes of genospecies Borrelia burgdorferi sensu lato isolated from rodents in Taiwan. J Clin Microbiol 1998; 36: 3127-3132.

30. Fuchs R, Jauris S, Lottspeich F, Preac-Mursic V, Wilske B, Soutschek E. Molecular analysis and expression of a Borrelia burgdorferi gene encoding a $22 \mathrm{kDa}$ protein $(\mathrm{pC})$ in Escherichia coli. Mol Microbiol 1992; 6: 503-509.

31. Higgins DG, Bleasby AJ, Fuchs R. CLUSTAL V: improved software for multiple sequence alignment. Comput Appl Biosci 1992; 8: 189-191.
32. Saitou N, Nei M. The neighbor-joining method: a new method for reconstructing phylogenetic trees. Mol Biol Evol 1987; 4: 406-425.

33. Anderson JF, Magnarelli LA, LeFebvre RB et al. Antigenically variable Borrelia burgdorferi isolated from cottontail rabbits and Ixodes dentatus in rural and urban areas. J Clin Microbiol 1989; 27: 13-20.

34. Oliver JH. Lyme borreliosis in the southern United States: a review. J Parasitol 1996; 82: 926-935.

35. Postic D, Ras NM, Lane RS, Hendson M, Baranton G. Expanded diversity among California Borrelia isolates and description of Borrelia bissettii sp. nov. (formerly Borrelia group DN127). J Clin Microbiol 1998; 36: 3497-3504.

36. Mathiesen DA, Oliver JH, Kolbert CP et al. Genetic heterogeneity of Borrelia burgdorferi in the United States. J Infect Dis 1997; 175: 98-107.

37. Liveris D, Gazumyan A, Schwartz I. Molecular typing of Borrelia burgdorferi sensu lato by PCR-restriction fragment length polymorphism analysis. J Clin Microbiol 1995; 33: 589-595.

38. Masuzawa T, Komikado T, Yanagihara Y. PCR-restriction length polymorphism analysis of the ospC gene for detection of mixed culture and for epidemiological typing of Borrelia burgdorferi sensu stricto. Clin Diagn Lab Immunol 1997; 4: 60-63.

39. Li M, Masuzawa T, Takada N et al. Lyme disease Borrelia species in northeastern China resemble those isolated from Far Eastern Russia and Japan. Appl Environ Microbiol 1998; 64: $2705-2709$. 